\title{
EDITORIAL
}

\section{Is There an Open-Access Future for GEOSCIENCE CANADA?}

\author{
Andrew Kerr \\ Department of Earth Sciences \\ Memorial University \\ St. John's, Newfoundland and Labrador, A1B 3X5, Canada \\ E-mail:akern@mun.ca
}

Almost exactly a year ago, I was trying to return home to Newfoundland with little understanding of what would unfold from the Global Pandemic that has since influenced - or more accurately, controlled - most aspects of our lives. I have read various opinion pieces about the 'positive side-effects of the pandemic' or similar constructs but, like many, I find it difficult to identify or enumerate these. But I can think of at least one development that relates to Geoscience Canada - for the last twelve months, we have functioned as an open access journal, with content freely available to all. This proved to be a help in producing the journal through 2020 - which certainly had its challenges - but we feel also that it helped to raise our profile in the Global Geoscience Community. As an editor soliciting contributions, it was wonderful to be able to refer potential authors directly to current or recent issues on our websites. To promise that any published article would be immediately available and could be freely distributed was also an asset. We hope that the impact of this increased visibility will assist us as we proceed through 2021, which likely will still pose many challenges. However, even before the pandemic, we were almost there - we had already taken an important step along the road to Open Access when the subscription window for Geoscience Canada articles went from two years to one, in conjunction with other journals of the Érudit consortium. This first issue of Geoscience Canada for 2021 is also fully Open Access, but this reflects specific arrangements for the papers that it contains; the previous policy will return for the remaining issues in volume 48. I view that reprise with some regret, so perhaps this is a good chance to revisit issues connected to a possible Open Access future and think about ways to achieve that goal. If, indeed, this is something that we really want to pursue. Nobody will be surprised to learn that this is a complex matter, or that issues of funding and sustainability lie at its core.

In 2016, soon after becoming editor, I wrote a commentary about Open Access (Kerr 2016) and much of what it contains remains true. At that time, a complete transition did not seem viable for us, but we had to consider ways to accommodate this growing trend. In the end, we opted for what is termed the "hybrid model", in which immediate Open Access is 'sold' to authors who desire it. Initially we had two options - immediate transfer, and transfer one year from publication, with a $50 \%$ discount for the latter. Following Érudit's decision that all affiliated content should be Open Access after one year, the higher rates were eliminated. Today, if you publish a paper with us that occupies 10 journal pages, the price tag for immediate Open Access is CAD \$ 1000 - a CAD \$ 500 flat-rate fee, and CAD \$ 50 per page. Even without accounting for currency exchange rates, this is much less than for most commercial journals, if indeed they offer such options. If you wonder how successful this approach proved, I might as well provide an honest answer: it largely failed. To my knowledge, we never received any purchases at the higher rate but when the policy was adjusted and rates were cut in half, we did gain revenue largely from Government science agencies who had funded the research in question. There was less interest in this option from the academic research community because we already met the one-year standard required by funding agencies, or from our many authors who do not enjoy financial support for research and writing. The response in the last two years is encouraging but it does not yet provide us with a route towards what we really need, i.e. a system that will allow us to make all content fully available, but at the same time survive and fund the hard work that has to go into every issue. How might we make that transition without digging our own financial grave? What advantages would full Open Access bring to Geoscience Canada and are they worth this potentially risky step? These are just some of the questions that we would need to consider.

As usual, the core issues relate to money. As an online journal, Geoscience Canada does not confront the high costs associated with hardcopy print runs. We are easily able to publish longer papers, and we can use colour imagery as widely as we or the authors choose. There is a general perception that online publishing costs next-to-nothing, but this view is wildly incorrect. The overall cost of producing the journal in 2020 was some $\$ 25,000$ and was down from previous years because Issues 1 and 2 were combined and our page count reduced. Like many smaller journals, our operations depend on efforts from largely unpaid volunteers, but those alone could not possibly sustain us. From submission to final appearance, there is a constant back-and-forth dialogue with authors, and also with reviewers of the paper; some papers go through review a sec- 
ond time, which adds to the time commitment and workload. The acceptance of a paper is just the start of another process, involving copy-editing and pre-layout. Illustrations often need additional work to make them legible or adjustment for page layout, and not all of this is done by the authors; a lot of it ends up on my desk, in addition to the role of Editor. The final steps produce the polished document with its integrated figures and tables, and then assemble the complete issue. The complexity of layout varies, but it is rare that the first edition is the final edition, and even rarer that last-minute corrections and fixes are not needed somewhere. The papers that eventually emerge by then have become familiar characters in our daily lives, and I mean that quite literally. Some of that effort comes from volunteer power, but this could never do all of it. The work of our Managing Editor, Cindy Murphy, and external services such as document layout and French translation are important components of our annual costs, and they are essential.

Clearly, the costs of production must at least be balanced by revenues. On paper, Geoscience Canada makes a small financial contribution to GAC, with annual revenues of some $\$ 40,000$ in 2020 . In the past, we have received some additional support via the Canadian Geoscience Foundation, and from other sources, which were provided to help us become selfsufficient. Income from Open Access charges is a small component of our overall revenue, and subscription income contributes most to this equilibrium. We still benefit from this, as the recent Open Access interlude was a temporary measure in response to the global impacts of the pandemic. This issue is at the core of any movement towards full open access - how do we replace that revenue on a long-term basis if it were to be discontinued?

Many Open Access journals have adopted a model that is essentially "author-pay" to cover the costs associated with publication. The authors of accepted papers - or agencies that support their research - pay an article processing fee, structured to reflect the length and/or complexity of the article, and eventual publication of the article is contingent on payment of the fee. It clearly works - at least on a multi-year basis - but there are many questions about such a model. The most obvious are editorial objectivity and the maintenance of standards for articles. If the revenue is directly tied to the number of paid contributions, it is only natural that some will question the quality of all the science or the integrity of peer review. The unsolicited emails that I frequently receive seeking submissions for such journals attest to a mass marketing effort on the part of some of them. Such a system would also favour those with greater research funding or personal resources, and disadvantages students, retired professionals, or other independent contributors. In a wider perspective, it also disadvantages many scientists from countries outside the wealthy, developed world. In many lower-income countries, funding for research is very difficult to obtain, and some of these fees would represent a major portion of the annual income for academic staff. Realistically, this author-pay model is not one that Geoscience Canada could seriously consider. We may not publish large numbers of papers, but we strive for high-quality, read- able articles, and are proud of what we publish. We also publish many solicited or invited articles and these are often written by individuals who may not have financial support. We cannot solicit papers with one hand and then later issue invoices with the other.

A second option is for Geoscience Canada to seek funding sources that can ultimately remove our dependence on subscription revenue. But what might such sources be? There are examples of larger organizations that receive voluntary financial contributions from those that they serve. Wikipedia and Mozilla are great examples in the world of online technology like many, I make extensive use of both, and have been willing to contribute a little at times. In this case, we would be looking more for a reader-pay concept that is not a formal subscription. Other potential contributors for an independent Canadian geoscience journal like us could include academic and government institutions (for example Geological Surveys) or private enterprise involved in the technical side of resource exploration and development. The payment of Open Access options over the last few years may in part have been recognition that our efforts do in the end save costs involved in internal publication of science by such agencies. It is not likely that single large donors could be found, and this might not even be desirable, but smaller contributions distributed widely might go some way to bridging the gap. I am not aware of any journals that raise money independently through methods such as gofundme.com, but neither am I aware of anything that would prevent us from trying such an approach. I have long pointed out that the cost of an individual subscription to Geoscience Canada is an order of magnitude less than the annual cost of one cup of coffee per work day from your preferred franchise. We would be more than happy to see some of those personal caffeine funds redirected to dissemination of geoscience research, I can assure you. There is only one way to find out if such a strategy might actually work and from what I understand of how such crowd-sourcing processes work, this is in the "next to nothing to lose" category.

A more conventional approach might be to look again at the current Open Access structure and present it in a different light. Many journals have not ventured along the road towards Open Access, but they continue to request page charges in order to support their operations. However, such charges are voluntary and are not required in order for a paper to be published, so this is not strictly an author-pay approach. The page charges requested by many journals are considerably higher than those in our current Open Access fee system, and in many cases bring fewer tangible benefits to the authors. In some cases, they do nothing to actually breach the subscription wall for readers, or they may impose restrictions on distribution and website posting. During my time working professionally for a Government Agency, few objections were ever raised about the payment of such page charges. Is it possible that we could reframe our current Open-Access surcharges in a manner akin to those of page charges, perhaps at a reduced rate? This would not have to be a stand-alone strategy, for it could be combined with other efforts to seek funding more widely from external sources. It is also something that we could try on 
an experimental basis over the next year or two, without any need to actually change existing policies. Any decision to alter or remove subscriptions would need to be considered very carefully because it is not readily reversible, but at least we would then have some basis on which to contemplate it.

Are there real advantages to becoming an open-access journal? What should we expect if we are ultimately able to make such a transition? Above all, do we really want to take such a step? The first and most obvious advantage is wider circulation and readership, which benefits authors and GAC as our parent organization. As editor, one of my main tasks is to solicit papers and contributions, but I freely admit that it is difficult to find the time to do as much of this as is really required. When I do so, I am commonly asked about the 'visibility' of Geoscience Canada and how widely a paper that we publish will actually be read and (most importantly) cited. This is understandable, especially for younger scientists who need to build and develop careers. Being able to say 'we are open to all' is a powerful statement to make in this context. The more readers who become aware of the high-quality articles that we strive to produce, the greater the chance of increasing unsolicited submissions to the journal, which will help to build our profile higher, and raise that all-important "impact factor". If there is one thing we would all love to see, it would be more articles in every single issue. But we must remember that the costs involved in producing the journal would grow with its article and page count, and there would be increased pressure on those who presently contribute their time and effort without payment. We need to think of ways to link an increased profile with potential for increased revenue, but such considerations are issues we would love to confront - If they emerge, it is a sign of accomplishment. In summary, any move towards full Open Access is a delicate balancing act, and one that needs to be approached very carefully. It is also an issue on which we would clearly benefit in receiving opinions from those who ultimately make the journal function - our authors and our readers. So, we would like to hear from you. And, of course, we would be delighted to receive manuscripts!

In closing, I wish to sincerely thank those who assist with the effort that goes into Geoscience Canada every year. In particular, I thank Cindy Murphy (Managing Editor), Bev Strickland (layout and design) Evelise Bourlon (French Translation), Peter Russell (graphic icons), Karen Dawe (GAC HQ Liaison) and also tireless volunteer copy editors Robert Raeside, Lawson Dickson, Stephen Amor and Janice Allen. We are always in need of volunteer support and are currently seeking section editors interested in continuing or developing thematic series papers. If you have ideas or interests in specific areas and have good persuasion skills to try out on your professional colleagues, we would be very interested to hear more from you.

Deanne van Rooyen is thanked for thoughts and suggestions that improved the hastily-written text of this contribution.

\section{REFERENCE}

Kerr, A., 2016, Open Access - Panacea or Pandora's Box?: Geoscience Canada, v. 43, p. 93-95, https://doi.org/10.12789/geocanj.2016.43.092.

\section{GEOLOGICAL ASSOCIATION OF CANADA}
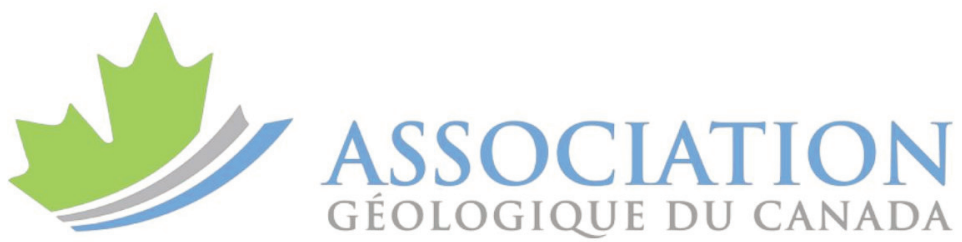

Please join the Geological Association of Canada in a virtual Celebration of Canadian Geoscience! This event will take place over several days in May 10-22,2021, and will showcase present and past medallists, our Sections, Divisions, and partner organizations. We will celebrate the Canadian Geoscience community at a time when we cannot gather together in our traditional events. All members are invited to attend as many of the talks as they wish, hear about new publications and upcoming conferences, and participate in the GAC Annual Business Meeting.

A detailed schedule will be announced in early April on our website and by email for members. All events will be scheduled between 2:30 to 4:30 pm Eastern time and will be approximately an hour long, hosted on zoom. As an example, join us for the presentation of this year's National medallists (Logan, Ambrose, Hutchison, and Neale medals) on May $14^{\text {th }}$, the Logan medallist talk on May $17^{\text {th }}$ and the GAC Annual Meeting on May $19^{\text {th }}$. Other events will include talks and medallists from Sections and Divisions, and events related to publications and something for students.
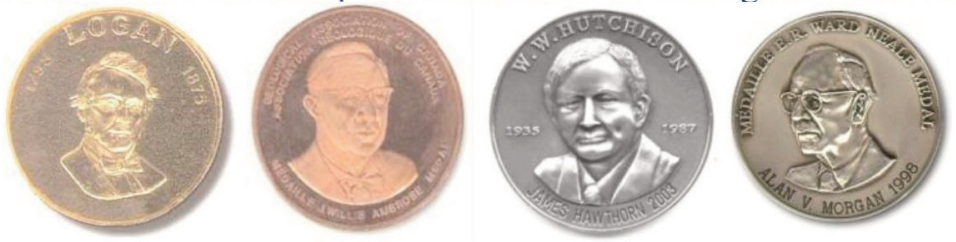


\section{GEOLOGICAL ASSOCIATION OF CANADA}

\section{(2020-2021)}

\section{CORPORATE MEMBERS}

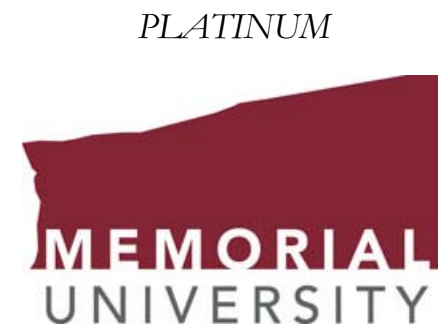

GOLD

NORTHWEST TERRITORIES GEOLOGICAL SURVEY

\section{SILVER}

\section{ROYAL TYRRELL MUSEUM}

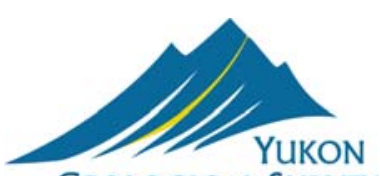

GEOLOGICAL SURVEY

NICKEL

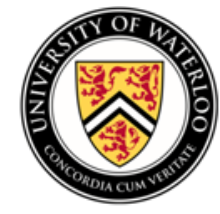

GEOSCIENCE CANADA AND THE GEOLOGICAL ASSOCLATION OF CANADA ARE GRATEFUL TO THE CANADLAN GEOLOGICAL FOUNDATION FOR THEIR FINANCLAL SUPPORT OF THIS JOURNAL

\section{OFFICERS}

\section{President}

Deanne van Rooyen Past President

Kathryn Bethune Vice-President

Alwynne Beaudoin Treasurer

Michael Michaud Acting Secretary

Rebecca Hunter

\section{Councillors}

Paul Alexandre Andrea Amortegui Alwynne Beaudoin Kathryn Bethune Stefanie Bruekner Hendrik Falck Alana Hinchey Rebecca Hunter Andy Kerr

Phil McCausland Michael Michaud Camille Partin Roger Paulen

Deanne van Rooyen Reg Wilson

\section{StANDiNg CommitTeES}

Communications: Rebecca Hunter

Finance: Michael Michaud

GAC Lecture Tours: Stefanie Bruekner

Publications: Roger Paulen Science Program: Phil McCausland

\section{Canadian Geological Foundation \\ Fondation \\ Géologique du Canada}

